American Journal of Applied Sciences 2 (5): 993-995, 2005

ISSN 1546-9239

(C) Science Publications, 2005

\title{
Minimization of Load Oscillations in Travelling Mechanisms of Cranes
}

\author{
Kamal Khandakji \\ Department of Electrical Engineering, Tafila Applied University College \\ Al Balqa' Applied University, Jordan
}

\begin{abstract}
The paper presents an analysis of suspended load (cargo) oscillations in traveling mechanisms of cranes. A special control algorithm has been developed in order to get minimum cargo oscillations in minimum transient time. Mathematical model simulating the effect of the suggested control algorithm on cargo oscillations has been developed. Two power electronic circuits applicable for AC drives with three-phase induction motors are suggested to obtain the required motion algorithm.
\end{abstract}

Key words: Cranes, travelling mechanisms, load (cargo) oscillations, control algorithm, dynamic modes

\section{INTRODUCTION}

It is known that cranes are characterized by cyclic operation consisting of lifting, traveling and lowering the cargo. The process of traveling the cargo may be achieved either by moving the crane carriage or by rotating the boom crane. In both cases, the starting or the stopping process of traveling the cargo is accompanied with some oscillations in the suspended cargo on which a long time can be spent in calm (see Fig. 1 and 2). Therefore it is important to use such a control algorithm so that the transient (starting or stopping) time is minimized, and the angle of deviation of the cargo from the vertical and its derivative are equaled zero in the end of the transient mode.

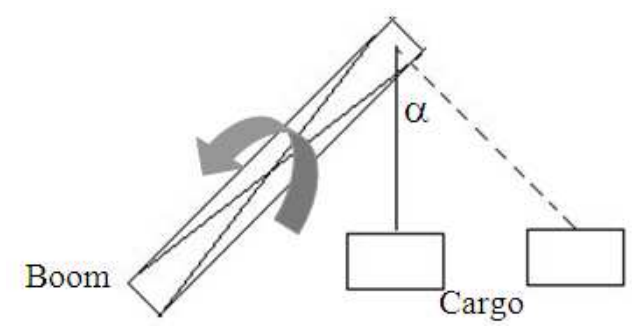

Fig. 1: Rotating the Crane Boom.

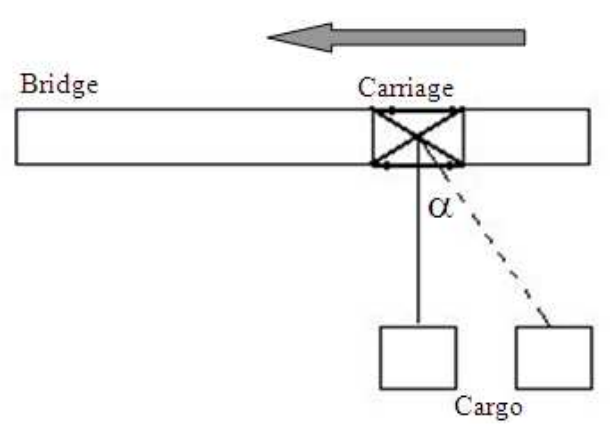

Fig. 2: Moving the Crane Carriage

\section{MATHEMATICAL ANALYSIS}

The frequency of the cargo oscillations depends on three factors: $m_{1}$ - the mass of the crane, $m_{2}$ - the mass of the cargo and $l$ - the length of the rope hoisting the cargo. It can be defined as follows (1):

$\Omega=\sqrt{\frac{g\left(m_{1}+m_{2}\right)}{l \cdot m_{1}}}$

The angle of cargo deviation $(\alpha)$ with respect to the vertical, the speed of the crane boom (or carriage ) $\left(\mathrm{V}_{1}\right)$ and the speed of the suspended cargo $\left(V_{2}\right)$ can be determined as follows:

$\alpha=\frac{F}{m g}(1-\cos \Omega \mathrm{t})+\alpha_{\mathrm{n}} \cos \Omega \mathrm{t}+\frac{\alpha_{n}^{\prime}}{\Omega} \sin \Omega \mathrm{t}$

$\mathrm{V}_{1}=\mathrm{V}_{1 \mathrm{n}^{-}} \alpha_{n}^{\prime} \frac{m_{2}}{m}(1-\cos \Omega \mathrm{t})+$

$\frac{m_{2}}{m_{1} \Omega}\left(\frac{F}{m}-\alpha_{\mathrm{n}} \mathrm{g}\right) \sin \Omega \mathrm{t}+\frac{F}{m}$

$\mathrm{V}_{2}=\mathrm{V}_{2 \mathrm{n}}+\frac{\alpha_{n}^{\prime} \cdot l \cdot m_{1}}{m}(1-\cos \Omega \mathrm{t})$

$+\frac{1}{\Omega}\left(\alpha_{\mathrm{n}} \mathrm{g}-\frac{F}{m}\right) \sin \Omega \mathrm{t}+\frac{F}{m} \mathrm{t}$

Where $\mathrm{m}=\mathrm{m}_{1}+\mathrm{m}_{2}$;

$\alpha_{n}$ and $\alpha_{n}^{\prime}-$ the initial values of the angle of deviation and its derivative at n-time interval respectively;

$\mathrm{V}_{1 \mathrm{n}}$ and $\mathrm{V}_{2 \mathrm{n}}$ - the initial values of the speed of the crane (boom or carriage) and the cargo at n-time interval respectively; 
$\mathrm{F}$ - the traveling force.

In order to minimize the transient time and cargo oscillations, Pontryagin maximum principle was used. It showed that the transient process (starting or stopping) should be carried out in three stages with a constant traveling force magnitude $\mathrm{F}$ (or motor torque $\mathrm{T}_{\mathrm{mot}}$ ) as shown in Fig. 3 .

From Fig. 3, it's seen that the total transient starting (or stopping) time $\left(\mathrm{t}_{\mathrm{s}}\right)$ of traveling the cargo can be divided into 3 intervals as follows:

$\mathrm{t}_{\mathrm{s}}=\mathrm{t}_{1}+\mathrm{t}_{2}+\mathrm{t}_{3}=\mathrm{T}_{\mathrm{ac}}+2 \mathrm{t}_{2}$

$\mathrm{t}_{1}=\mathrm{t}_{3}$

$\mathrm{T}_{\mathrm{ac}}=\mathrm{V}_{13}\left(\mathrm{~m}_{1}+\mathrm{m}_{2}\right) / \mathrm{F}_{\mathrm{m}}$

where, $\mathrm{T}_{\mathrm{ac}}$ - acceleration time required for the boom (carriage) to reach the given (steady-state) speed under constant modulo motor torque $\mathrm{T}_{\mathrm{m}}$ or force $\mathrm{F}_{\mathrm{m}}$.

Time interval $t_{2}$ can be found using the following equation:

$\sin \Omega\left(\mathrm{t}_{2}+\mathrm{T}_{\mathrm{ac}} / 2\right)=2 \sin \left(\Omega \mathrm{t}_{2} / 2\right)$

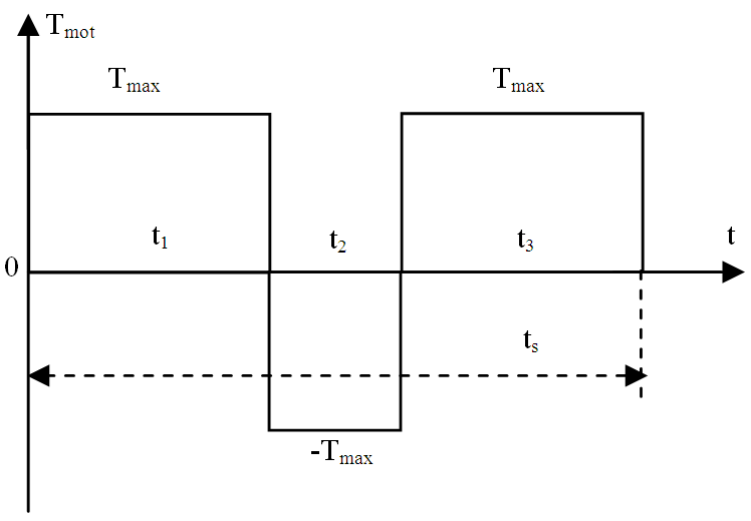

(a)

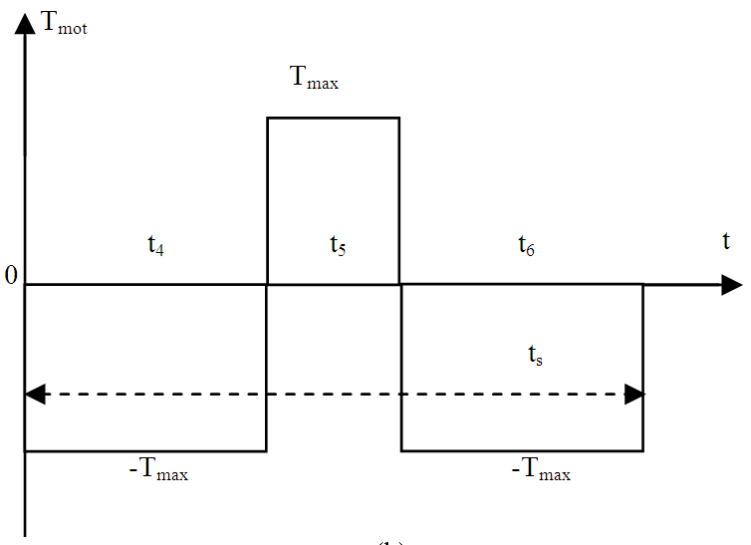

(b)

Fig. 3: Diagram of Motor Torque for Optimal Starting (a) and Stopping (b) of Crane Traveling Drive

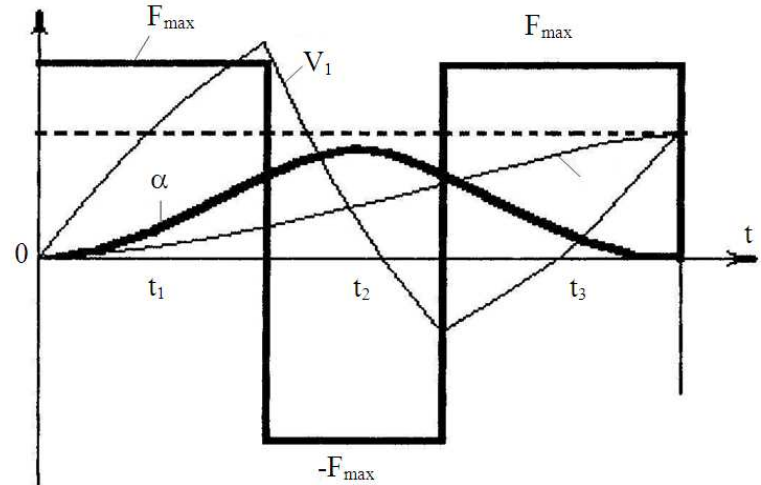

Fig. 4: Simulation of the Starting Process of Traveling a Cargo

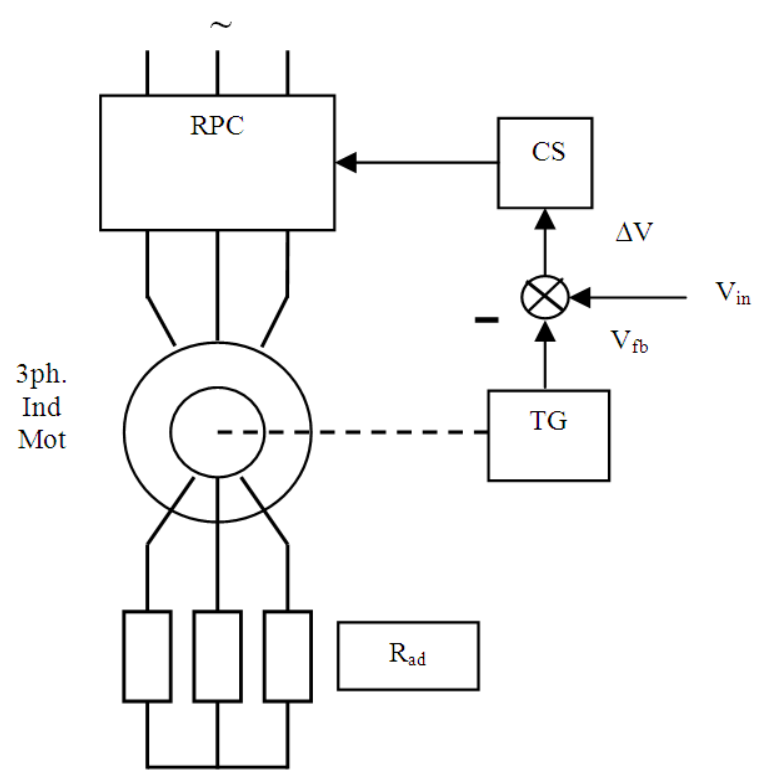

Fig. 5: Block-diagram of the Thyristor-Reversing Power Controller System.

Using equations (1-7) the starting process of a specific traveling mechanism was simulated. The results of simulation are in Fig. 4.

As seen from Fig. 4, using the above shown traveling torque (force) algorithm in the transient process, the angle of load deviation $\alpha$ and its derivative equal zero at the end of the transient. It is also seen that the cargo speed $\mathrm{V}_{2}$ reaches its steadystate value $\mathrm{V}_{13}$ in a manner different from the boom (or carriage) speed $\mathrm{V}_{1}$.

Therefore it would be very important to design such a power circuit to feed the driving motor and control the motor torque in the transient modes to get minimum load oscillations. For this purpose, two AC drive systems with three-phase induction motor are suggested below $(2,3)$. 


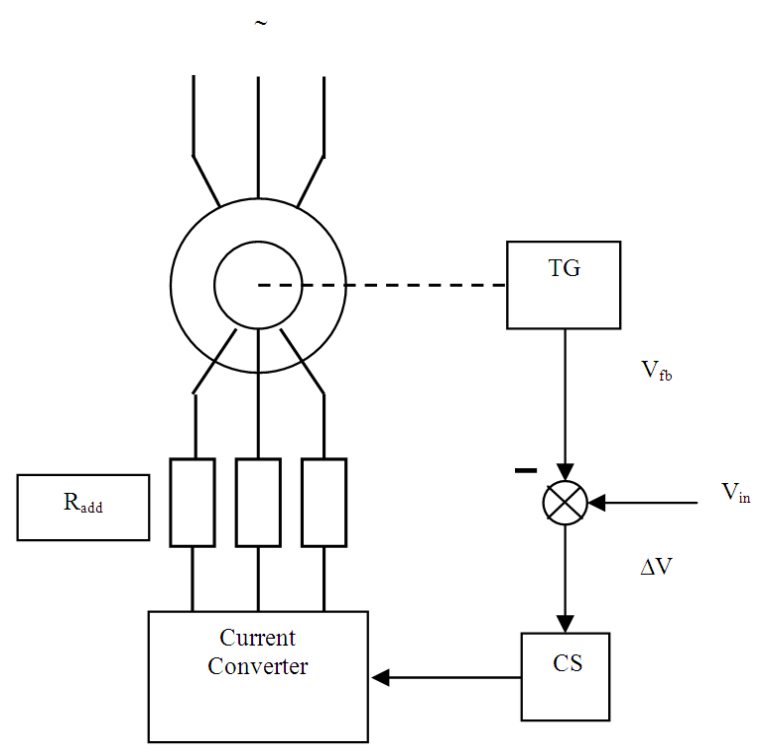

Fig. 6: Block-diagram for the Thyristor-Current Converter System.

The first system uses thyristor-reversing power controller (RPC) feeding the starter circuit, additional resistors in the rotor circuit, speed feedback using tachogenerator (TG) and control system (CS). The second system uses thyristor-current converter with additional resistors in the rotor circuit, speed feedback and control system (CS). The block-diagrams for both systems are shown in Fig. 5 and 6, respectively.

\section{CONCLUSION}

Load (cargo) oscillations induced in traveling mechanisms of cranes can be eliminated using the above discussed force (torque) algorithm in transients. Oscillations minimization is important for mechanical stability, transient-time minimization and therefore the crane productivity in general.

\section{REFERENCES}

1. Zdrozis Cosmos Petros. [2004], "Vibration of Double-Mass Electromechanical System of Hoisting Mechanism" Electromechanical Engineering and Electrical Equipment Vol. 62, pp.: 49-52. Thessaloniki Institute of Technology. Thessaloniki - Greece.

2. Dewan S.B., Slemon G.R., Straughen A. [1984], Power Semiconductor Drives. A WileyInterscience Publications. John Wiley and Sons.

3. Mummadi Veerachary. [2002], "Optimal control strategy for a current source inverter fed induction motor" Computers and Electrical Engineering Pergamon - Elsevier. Vol. 28, pp.:255-267 